\title{
Accident Prediction Model at Unsignalized Intersection Using Multiple Linear Regression Method
}

\author{
Oghoyafedo N. K. ${ }^{1, *}$, Ehiorobo J. O. ${ }^{1}$, Nwankwo E. ${ }^{1}$ \\ ${ }^{1}$ Department of Civil Engineering, University of Benin, Benin City, Nigeria \\ Corresponding Author:*nosakhare.oghoyafedo@uniben.edu
}

\begin{abstract}
The issue of road accidents is an increasing problem in developing countries. This could be due to increasing road traffic/vehicle occupancy, geometric characteristics and road way condition. The factors influencing accidents occurrence are to be analysed for remedies. The purpose of this research is to develop an accident prediction model as a measure for future study, aid planning phase preceding the designed intervention, enhance the production of updated design standards to enable practitioners design unsignalized intersection for optimal safety, reduce the number of accidents at unsignalized intersections. Five intersections were selected randomly within Benin City and traffic count carried out at these intersections as well as geometric characteristics and roadway conditions. The prediction model was developed using multiple linear regression method and the standard error of estimate was computed to show how close the observed value is to the regression line. The model was validated using coefficient of multiple determination. The establishment of the relationship between accidents and traffic flow site characteristics on the other hand would enable improvement to be more realistically accessed. This study will also enhance the production of updated design standards to enable practitioners design unsignalized intersection for optimal safety, reduce the number of accidents at unsignalized intersections.
\end{abstract}

Keywords: Unsignalized Intersection, Multiple Regression, Dependent Variable, Independent Variable, Accident Rate

\subsection{Introduction}

Accident can be defined as anything which happens by chance, anything occurring unexpectedly undersigned (Odugbemi, 2010). Road accident do not simply happen, they are caused. Nigeria has a high road traffic accident rate as well as one of the largest numbers of death per 10,000 vehicles (Sheriff, 2009). Nigeria is ranked second-highest in the rate of road accidents among 193 countries of the world (Agbonkhese et al., 2013). (Oladepo and Brieger, 1986) had argued that three-quarters of all accidents on Nigerian roads involve fatalities. The incidence of fatal road accidents in Nigeria is phenomenal.

Trend analysis of fatal road accidents between June 2006 and May 2014 using Nigeria Watch database record gives 15,090 lives lost to fatal road accidents in 3,075 events, highest fatality occurred in 2013 (2,061 deaths), a 2.8\% increase from the 2012 record of 1,652 deaths (Ukoji, 2014). Road accidents can happen in many forms. Generally, road traffic accident can be categorized into four common type: where the driver collide with another vehicle or a roadside object, when the driver leaves the lane where they are in, accidents at junctions include rear-end collision and angle or side impacts, accidents that involving pedestrians and cyclists and accident that collide with animals (Nicholas et al., 2003).

Accident at intersection gives high impact to the road users. In urban areas where the traffic volume are high, intersection provided must accommodate the high volume for turning movement that traverse to large areas. For this situation, the channelization is an effective means to make sure that the road intersection provides safety. Intersection channelization is used to separate turn lanes from through lane that consist of solid white liners or barrier which guide the traffic so that the vehicle can safely negotiate the complex intersection. (Nicholas et al., 2003) 
An accident prediction model is generally an algorithm pitting a dependent variable against several independent variables, each of which is assigned a constant. The dependent variable in an accident prediction model is the number of accidents, while the independent variables may be quantitative variables such as traffic flow, section length, pavement surface condition, infrastructures geometric characteristics, lighting and driver behaviours (Rokade et al., 2010).

The estimation of the number of accidents is not only performed to determine the effect of design elements, but may also be used in estimating accident reductions attributed to changes in the cross section of roads, predicting accident costs and as a measure of safety (Manan, 2011).

\subsection{Materials and Methods}

\subsection{Data Collection}

Selection of sample intersections was made based on stratification by traffic flow and intersection characteristics to ensure that a wide range of flows and intersection characteristics were captured. For each intersection, detailed information regarding accidents, traffic flow, geometric characteristics, traffic characteristics etc. were collected.

Accident data covering the period of 2011 - 2015 inclusive of the intended selected intersection were retrieved from the Federal Road Safety Corps head office. The database was compiled from police using a standard accident report form. Traffic flow data collected included vehicle counts from both major and minor road not classified by type of vehicle and turning movement and spot speeds of vehicles as they approached the intersection area along the major arms. Traffic counts was conducted during the morning and evening peak periods from 7:00am to 9:00am hours and from 4:00pm to 6:00pm hours, respectively.

Intersection inventories were carried out to collect information relating to the site details. The information collected included intersection layout, type of major and minor roads (i.e whether single or dual carriageway), number of lanes, width of lanes etc. Also information regarding surface condition of the roadway and shoulder were noted based on visual inspection and as well the conditions of the drainage facilities were obtained from site.

\subsection{Prioritization of Secondary Data}

Prioritization involves assigning suitable weights to different factors so as to achieve a desired result. In this model, the various factors which tend to influence the occurrence of accidents on roads are assigned weights on a scale of $0-10$ in such a manner that the factors which tend to increase the probability of the accidents have lower weights. In order to prioritize roads for occurrence of accidents, various factors were considered and the weights assigned to them as shown in Table 1 . The final weight assigned to each road link was obtained by adding all the individual weights and normalizing the value using maximum weight (in this case 130) that can be assigned.

Hence,

Total weight $=(\Sigma$ Individual Weights $) \times 100 / 130)$ 
Table 1: Factors used in prioritization with their weights

\begin{tabular}{|c|c|c|c|}
\hline $\mathbf{S} / \mathbf{N}$ & Factors Affecting Occurrence of Accident & Possible Variation & Rank \\
\hline \multirow{4}{*}{1} & \multirow{4}{*}{ No of lanes in each direction } & 4 & 10 \\
\hline & & 3 & 8 \\
\hline & & 2 & 6 \\
\hline & & 1 & 4 \\
\hline \multirow{4}{*}{2} & \multirow{4}{*}{ Number of vehicles per day } & Less than 1000 & 10 \\
\hline & & Less than 2500 & 8 \\
\hline & & Less than 5000 & 6 \\
\hline & & Greater than 5000 & 4 \\
\hline \multirow{5}{*}{3} & \multirow{5}{*}{ Width of Road } & More than $15 \mathrm{~m}$ & 10 \\
\hline & & $10.1-15 \mathrm{~m}$ & 8 \\
\hline & & $7.5-10.5 \mathrm{~m}$ & 6 \\
\hline & & $6.1-7.5 \mathrm{~m}$ & 4 \\
\hline & & Less than $6 \mathrm{~m}$ & 2 \\
\hline \multirow{2}{*}{4} & \multirow{2}{*}{ Presence of Shoulder } & Yes & 10 \\
\hline & & No & 4 \\
\hline \multirow{2}{*}{5} & \multirow{2}{*}{ Surface condition of road } & Flexible & 10 \\
\hline & & Rigid & 8 \\
\hline \multirow{4}{*}{6} & \multirow{4}{*}{ Drainage condition } & Good & 8 \\
\hline & & Satisfactory & 6 \\
\hline & & Poor & 4 \\
\hline & & No Drainage & 2 \\
\hline \multirow{2}{*}{7} & \multirow{2}{*}{ Presence of traffic lights } & Yes & 10 \\
\hline & & No & 4 \\
\hline \multirow{2}{*}{8} & \multirow{2}{*}{ Provision of median } & Yes & 10 \\
\hline & & No & 4 \\
\hline \multirow{2}{*}{9} & \multirow{2}{*}{ Roundabout } & Yes & 10 \\
\hline & & No & 4 \\
\hline \multirow{5}{*}{10} & \multirow{5}{*}{ Length of road before } & $100 \mathrm{~m}$ & 10 \\
\hline & & $300 \mathrm{~m}$ & 8 \\
\hline & & $500 \mathrm{~m}$ & 6 \\
\hline & & $700 \mathrm{~m}$ & 4 \\
\hline & & $1000 \mathrm{~m}$ & 2 \\
\hline \multirow{7}{*}{11} & \multirow{7}{*}{ Conflict points } & 24 & 10 \\
\hline & & 17 & 9 \\
\hline & & 16 & 8 \\
\hline & & 13 & 7 \\
\hline & & 12 & 6 \\
\hline & & 11 & 5 \\
\hline & & 7 & 4 \\
\hline \multirow{4}{*}{12} & & Heavy vehicle & 10 \\
\hline & Tyne of Vehicles & Buses/Truck & 8 \\
\hline & 1ype or venicles & Car & 4 \\
\hline & & Two wheelers & 1 \\
\hline & & Good & 10 \\
\hline 13 & visibility & Average & 6 \\
\hline 13 & visibility & Poor & 4 \\
\hline & & Very poor & 2 \\
\hline
\end{tabular}

\subsection{Weighted Average}

The various factors considered for affecting the occurrence of accidents may not have similar effect. Every factor will have a different level of involvement for an accident to take place. For example Presence of Shoulder and Average Annual Daily traffic (AADT) cannot be given same weightage because more traffic may be a greater factor in occurrence of accident as compared to whether a shoulder is present on the side of a road or not. Table 2 shows the method of weighing. 
Table 2: Classification of weights

\begin{tabular}{cc}
\hline Weight & Accident prone level \\
\hline 1 & Very Low \\
2 & Low \\
3 & Medium \\
4 & High \\
5 & Very High \\
\hline
\end{tabular}

\subsection{Regression Analysis}

In statistics, regression analysis includes any techniques for modelling and analyzing several variables, when the focus is on the relationship between a dependent variable and one or more independent variables. More specifically, regression analysis helps us understand how a typical value of the dependent variable changes when any one of the independent variables is varied, while the other independent variables are held fixed. Most commonly, regression analysis estimates the conditional expectation of the dependent variable given the independent variables - that is, the average value of the dependent variable when the independent variables are held fixed. The regression equation for the model developed is given by Equation 2 .

$Y=a_{0}+a_{1} X_{1}+a_{2} X_{2}+a_{3} X_{3}+a_{4} X_{4}+a_{5} X_{5}+a_{6} X_{6}+a_{7} X_{7}+a_{8} X_{8}+a_{9} X_{9}+a_{10} X_{10}+a_{11} X_{11}+a_{12} X_{12}+$ $\mathrm{a}_{13} \mathrm{X}_{13}$

The dependent variable used in the model is the Number of Accidents (Y). The independent variables used in the model include:
i. Major Traffic $\left(\mathrm{X}_{1}\right)$
ii. Minor Traffic $\left(\mathrm{X}_{2}\right)$
iii. Turning traffic $\left(\mathrm{X}_{3}\right)$
iv. Approach Width $\left(\mathrm{X}_{4}\right)$
v. Presence of shoulder $\left(\mathrm{X}_{5}\right)$
vi. Turning Radius $\left(\mathrm{X}_{6}\right)$
vii. Speed $\left(\mathrm{X}_{7}\right)$
viii. Major Road Number of Lanes $\left(\mathrm{X}_{8}\right)$
ix. Minor Road Number of Lanes $\left(\mathrm{X}_{9}\right)$
x. Roadway Surface Condition $\left(\mathrm{X}_{10}\right)$
xi. Visibility $\left(\mathrm{X}_{11}\right)$
xii. Number of Legs $\left(\mathrm{X}_{12}\right)$

\subsection{Model Validation}

The validation of the model was carried out as follows:

i. By finding the Coefficient of Determination $\left(\mathrm{R}^{2}\right)$

ii. By the comparison of results of total number of accidents found by model with the data obtained from Federal Road Safety Corps.

Coefficient of determination $\left(\mathrm{R}^{2}\right)$ is a number that indicates the proportion of the variance in the dependent variable that is predictable from the independent variable. It is a statistic used in the context of statistical models whose main purpose is either the prediction of future outcomes or the testing of hypotheses, on the basis of other related information. It provides a measure of how well observed outcomes are replicated by the model, based on the proportion of total variation of outcomes explained by the model.

The value of $\mathrm{R}^{2}$ lies between 0 and 1, i.e. $0 \leq \mathrm{R} \leq 1$ and it is given by Equation (3).

$$
\mathrm{R}^{2}=\frac{S S_{r e g}}{S S_{t o t}}==\frac{S S_{r e g} / n}{S S_{t o t} / n}
$$


In this form $\mathrm{R}^{2}$ is expressed as the ratio of the explained variance (variance of the model's predictions, which is $\mathrm{SS}_{\text {reg }} / \mathrm{n}$ ) to the total variance (sample variance of the dependent variable, which is $\mathrm{SS}_{\text {tot }} / \mathrm{n}$ ). Where

$$
\begin{aligned}
& \mathrm{SS}_{\mathrm{reg}}=\sum_{i}\left(f_{i}-\bar{\Upsilon}\right)^{2} \\
& \mathrm{SS}_{\mathrm{tot}}=\sum_{i}\left(y_{i}-\bar{\Upsilon}\right)^{2}
\end{aligned}
$$

$R^{2}$ is a statistic that will give some information about the goodness of fit of a model. In regression, the $R^{2}$ coefficient of determination is a statistical measure of how well the regression line approximates the real data points. An $R^{2}$ of 1 indicates that the regression line perfectly fits the data.

\subsection{Previous Related Studies}

Neumann and Glennon (1982) described a theoretical model that relates accident on crest curves to available sight distance. The development of this model was not based on accident data, rather the model relied on intuitively logical relationship and engineering judgment. The model is presented in Equation 6.

where,

$$
\mathrm{N}=\mathrm{ARH}(\mathrm{L})(\mathrm{V})+\mathrm{ARh}(\mathrm{Lr})(\mathrm{V})\left(\mathrm{F}_{\mathrm{ar}}\right)
$$

$\mathrm{N}=$ Number of accident on a segment of highways containing a crest curve.

$\mathrm{ARH}=$ Average accident rate for specific highways

$\mathrm{L} \quad=$ Length of highway segment in miles.

$\mathrm{V}=$ Traffic volumes in millions of vehicles.

$\mathrm{L} \quad=$ Length of restricted sight distance in miles

$\mathrm{F}_{\mathrm{ar}} \quad=$ A hypothetical accident rate factor that varies according to both the severity of the sight restriction and the nature of the hidden hazard.

Zegeer et al (1992) developed an accident prediction model (Equation 7) for the 1991 FHWA study cost- effective improvements for horizontal curves.

where,

$$
\mathrm{A}=\left[(1.552)(\mathrm{L})(\mathrm{V})+(0.014(\mathrm{D})(\mathrm{V})-(0.012)(\mathrm{S})(\mathrm{V})](0.978)^{\mathrm{W}}\right]
$$

$\mathrm{A}=$ number of total accidents on the curve in 3 years period

$\mathrm{L}=$ length of curves

$\mathrm{V}=$ volume of vehicles in million vehicles passing through (both direction) in a 5 Year time

$\mathrm{D}=$ degree of curve

$\mathrm{S}=$ presence of spiral

$\mathrm{W}=$ width of roadway (twice the lane plus shoulder width) on the curve.

To evaluate the combined effect of road elements, Transportation and Research Laboratory (TRRL) carried out research work in Kenya and Jamaica. The equations developed in this study are presented in Equations 8 (a-d).

$$
\begin{aligned}
& \mathrm{Y}=1.45+1.02 \mathrm{X}_{5}+.017 \mathrm{X}_{3}(\mathrm{KENYA}) \\
& \mathrm{Y}=1.09+0.031 \mathrm{X}_{3}+0.62 \mathrm{X}_{5}+0.0003 \mathrm{X}_{4}+0.062 \mathrm{X}_{2}(\mathrm{JAMICA}) \\
& \mathrm{Y}=5.77+0.755 \mathrm{X}_{1}+0.275 \mathrm{X}_{5}(\mathrm{JAMICA}) \\
& \mathrm{Y}=5.77+0.755 \mathrm{X}_{1}+0.275 \mathrm{X}_{5}(\mathrm{JAMICA})
\end{aligned}
$$

where,

$$
\begin{array}{ll}
\mathrm{Y} & =\text { rate per million vehicle kilometer per year } \\
\mathrm{X} 1 & =\text { road width }(\mathrm{m}) \\
\mathrm{X} 2 & =\text { vertical curvature }(\mathrm{m} / \mathrm{Km}) \\
\mathrm{X} 3 & =\text { horizontal curvature }(\text { degree} / \mathrm{Km}) \\
\mathrm{X} 4 & =\text { surface irregularity }(\mathrm{mm} / \mathrm{Km}) \\
\mathrm{X} 5 & =\text { junctions per } \mathrm{Km} .
\end{array}
$$

Zegeer et al (1995) developed Accident Relationships of Roadway Width on low-Volume Roads Horizontal curves represent a considerable safety problem on rural two lane highways. Accident studies further indicated that curves experience a higher accident rate than do tangents, with rates that range 
from one and a half to four times higher than similar perhaps be more important in light of improvements being made related to resurfacing, restoration, and rehabilitation projects, commonly known as the 3R program. Total accident rate was given by Equation 9 .

$$
\text { Accident }=(\text { ADT })(\text { Length })(1.94+0.24 \text { Deg-0.026Width-0.25Spirals })
$$

Miranda-Moreno et al (2005) developed Alternative Risk Models for Ranking Locations for Safety Improvement. The authors compared the performance and practical implications of these models and ranking criteria when they are used for identifying hazardous locations.

Brown et al (2006) considered the effects of access control on safety on urban arterial streets. Access control techniques are used to improve traffic performance and safety on highways. One important benefits of access control is improved safety. The objective of this research was to develop regression models to predict crash frequencies on urban multilane arterial segments.

Fajaruddin et al (2008) did his study on block spot study and accident prediction model using multiple regression linear models. The study area was federal Route (FT50) Batu Pahat - Ayer Hitam. The regression model is given by Equation 10 which had $\mathrm{R}^{2}$ of 0.9987 .

where,

$$
\log _{\mathrm{e}}(\mathrm{APW})^{0.5}=0.0212(\mathrm{AP})+0.0007\left(\mathrm{HTV}^{0.75}+\mathrm{GAP}^{1.25}\right)+0.0210\left(85_{\mathrm{th}} \mathrm{PS}\right.
$$

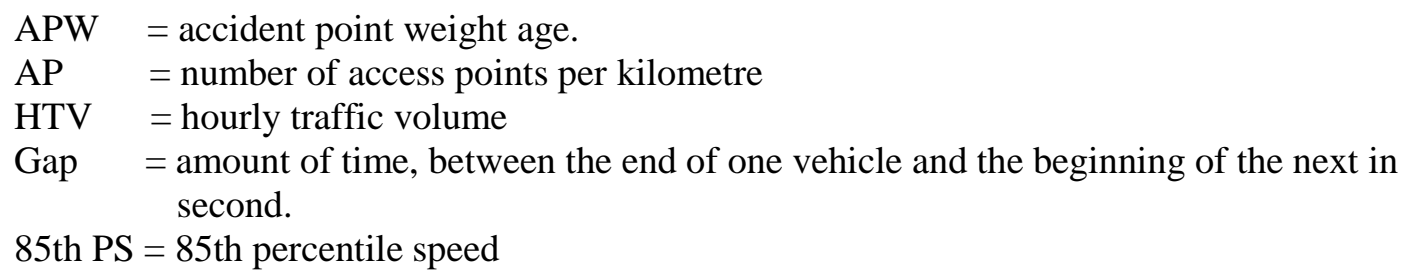

Fajaruddin et al (2008) developed a model for Black Spot Study and Accident prediction Model using Multiple Linear Regression. This approach is considered to be helpful for strengthening freeway management and reducing the likelihood of incidents. The freeway incident model developed in this study can constitute a useful decision support tool for analysis of traffic accident and the implementation of freeway patrol systems.

Ali et al (2009) used fractional factorial method for the sensitivity analysis of accident prediction model. The evaluation of sensitivity analysis indicated that average daily traffic (ADT), lane width (W), width of paved shoulder (PA), median $(\mathrm{H})$ and their interactions (i.e., ADT-W, ADT-PA and ADT-H) has significant effects on numbers of accidents. The effects due to each parameter and parameter interactions are estimated using Equation 11.

$$
E_{j}=S E_{j}=S_{i j}\left(X_{i}\right) / N_{j}
$$

In which Ej represent the effect of the jth factor (i.e., in jth column), $n$ the total number of experimental runs (i.e., $n=8$ ), Sij represents the sign in row $\mathrm{i}$ and column $\mathrm{j}, \mathrm{Xi}$ represents the value of the prediction variable obtained from the ith experimental run and $\mathrm{N}$ jis the number of "+" signs in column $\mathrm{j}$. Accident prediction model developed is given by Equation 12 .

$$
\mathrm{A}=0.0019(A D T)^{0.882}(0.879)^{\mathrm{w}}(0.919)^{\mathrm{PA}}(0.932)^{\mathrm{up}}(1.232)^{\mathrm{H} *}(0.882)^{\mathrm{T} 1}(1.322)^{\mathrm{T} 2}
$$

Velmajasiniene et al (2011) analysis of accidents prediction feasibility on the roads of Lithuania. Modelling of the road accidents was carried out based on 1997-2011. Data on fatal \& injury accidents on the main roads enabled the construction of mathematical models for the optimum selection of road safety improvement measures. One of the constructed mathematical models (Equation 13) allowed optimal selection of road safety improvement measures to reduce the number of people killed under unrestricted amount of trends.

$$
\mathrm{YS}=193.52+0.2 \mathrm{t}-67.7 \mathrm{t} 1-69.54 \mathrm{t} 2-14.48 \mathrm{t} 3
$$


where

$\mathrm{Y}=$ forecasted average value

$\mathrm{T}=$ trend variable $\mathrm{Ti}$ variable taking the value in the quarter 1 of the year $\&$ value 0 in the other quarter the fourth quarter at the year is corresponding by the value of variable.

\subsection{Regression Analysis of Accident Prediction at Unsignalized Intersection}

The independent variables are variables that measures and influences the outcome (dependent variable) of a mathematical or statistical model. They are independent of each other. They can constantly and intentionally change to observe their effect on the dependent variable. Table 3 shows the values of the independent variables selected for project work.

Table 3: Independent Variables of the Accident Prediction Model

\begin{tabular}{llccccc}
\hline S/N & Predictors & $\begin{array}{c}\text { PZ } \\
\text { Intsn. }\end{array}$ & $\begin{array}{c}\text { RCC } \\
\text { Intsn. }\end{array}$ & $\begin{array}{c}\text { NNPC } \\
\text { Intsn. }\end{array}$ & $\begin{array}{c}\text { CJ } \\
\text { Intsn. }\end{array}$ & $\begin{array}{c}\text { BBP } \\
\text { Intsn. }\end{array}$ \\
\hline 1 & Major Traffic & 5942 & 5906 & 4986 & 4110 & 4016 \\
2 & Minor Traffic & 660 & 1000 & 1684 & 400 & 820 \\
3 & Turning Traffic & 368 & 324 & 595 & 80 & 300 \\
4 & Approach Width & 10.46 & 10.23 & 10.34 & 8.42 & 7.8 \\
5 & Number of Legs & 3 & 3 & 3 & 3 & 3 \\
6 & Surface Condition & Flexible & Flexible & Flexible & Flexible & Flexible \\
7 & Speed & 63.008 & 56.500 & 58.900 & 58.716 & 45.23 \\
8 & Presence of Shoulder & NO & NO & NO & YES & YES \\
9 & Traffic Light & NO & NO & NO & NO & NO \\
10 & Lighting Condition & Very Poor & Very Poor & Very Poor & Very Poor & Very Poor \\
11 & Number of Lanes & 3 & 3 & 3 & 3 & 3 \\
12 & Drainage Condition & Poor & Poor & Satisfactory & Satisfactory & No Drainage \\
13 & Frequent Vehicle on the Road & Cars & Cars & Cars & Cars & Cars \\
\hline
\end{tabular}

\subsection{Prioritization value of the Independent Variables}

Prioritization involves assigning suitable weights to different factors that influences accident occurrence so as to achieve a desired result. Table 4 below shows the prioritized value of the accident predictors (independent variables).

Table 4: Prioritized Value of the Independent Variables

\begin{tabular}{clccccc}
\hline S/N & Predictors & $\begin{array}{c}\text { PZ } \\
\text { Intsn. }\end{array}$ & $\begin{array}{c}\text { RCC } \\
\text { Intsn. }\end{array}$ & $\begin{array}{c}\text { NNPC } \\
\text { Intsn. }\end{array}$ & $\begin{array}{c}\text { CJ } \\
\text { Intsn. }\end{array}$ & $\begin{array}{c}\text { BBP } \\
\text { Intsn. }\end{array}$ \\
\hline 1 & Major Traffic & 4 & 4 & 6 & 6 & 6 \\
2 & Minor Traffic & 10 & 8 & 8 & 10 & 10 \\
3 & Turning Traffic & 10 & 10 & 10 & 10 & 10 \\
4 & Approach Width & 8 & 8 & 8 & 6 & 6 \\
5 & Number of Legs & 5 & 5 & 5 & 5 & 5 \\
6 & Surface Condition & 10 & 10 & 10 & 10 & 10 \\
7 & Speed & 6 & 6 & 6 & 6 & 6 \\
8 & Presence of Shoulder & 4 & 4 & 4 & 10 & 10 \\
9 & Traffic Light & 4 & 4 & 4 & 4 & 4 \\
10 & Lighting Condition & 2 & 2 & 2 & 2 & 2 \\
11 & Number of Lanes & 8 & 8 & 8 & 8 & 8 \\
12 & Drainage Condition & 4 & 4 & 6 & 6 & 2 \\
13 & Frequent Vehicle on the Road & 4 & 4 & 4 & 4 & 4 \\
\hline
\end{tabular}




\subsection{Weightage Point of the Independent Variable}

This has to do with ranking of the prioritized values on a scale of $1-5$ in such a manner that the factors which tend to increase the probability of accidents have higher weights. The final weight assigned to each prioritized values of the independent variables is obtained by adding all the individual weights and normalizing the value using maximum weight (in this case 130) that can be assigned. Table 5 shows the weightage point of the prioritized values. Table 6 shows the accident record at five different intersections within Benin City in five years accident record. The accident record per annum will form the bases of our dependent variable. The data in the table above were obtained from the head quarter of the Federal Road Safety Corps.

Table 5: Weightage Point of the Prioritized Value of the Independent Variables

\begin{tabular}{cccccccccccccc}
$\mathbf{Y}$ & $\mathbf{X}_{\mathbf{1}}$ & $\mathbf{X}_{\mathbf{2}}$ & $\mathbf{X}_{\mathbf{3}}$ & $\mathbf{X}_{\mathbf{4}}$ & $\mathbf{X}_{\mathbf{5}}$ & $\mathbf{X}_{\mathbf{6}}$ & $\mathbf{X}_{\mathbf{7}}$ & $\mathbf{X}_{\mathbf{8}}$ & $\mathbf{X}_{\mathbf{9}}$ & $\mathbf{X}_{\mathbf{1 0}}$ & $\mathbf{X}_{\mathbf{1 1}}$ & $\mathbf{X}_{\mathbf{1 2}}$ & $\mathbf{X}_{\mathbf{1 3}}$ \\
\hline 79 & 4 & 2 & 2 & 3 & 4 & 2 & 4 & 4 & 4 & 5 & 3 & 4 & 4 \\
69 & 4 & 3 & 2 & 3 & 4 & 3 & 4 & 4 & 4 & 5 & 4 & 3 & 3 \\
25 & 4 & 3 & 2 & 4 & 3 & 2 & 3 & 4 & 4 & 5 & 3 & 4 & 3 \\
39 & 3 & 2 & 2 & 3 & 4 & 2 & 3 & 2 & 3 & 5 & 3 & 3 & 4 \\
57 & 4 & 2 & 2 & 3 & 4 & 2 & 4 & 2 & 4 & 4 & 3 & 5 & 4 \\
\hline
\end{tabular}

Table 6: Total Accident at Selected Intersections in Five years Accident record (Courtesy of FRSC)

\begin{tabular}{clc}
\hline S/N & Name of Location & Total Accident \\
\hline 1 & PZ Intersection & 79 \\
2 & RCC Intersection & 69 \\
3 & NNPC Intersection & 25 \\
4 & College Road Intersection & 39 \\
5 & Benin Bye Pass Intersection & 57 \\
\hline
\end{tabular}

\subsection{Formulation of Regression Equation}

The regression equations were thereafter formed as presented in Equations $14-27$ :

$$
\begin{aligned}
& 5 a_{0}+19 a_{1}+12 a_{2}+10 a_{3}+16 a_{4}+19 a_{5}+11 a_{6}+18 a_{7}+16 a_{8}+19 a_{9}+24 a_{10}+16 a_{11}+19 a_{12}+18 a_{13}=269 \\
& 19 a_{0}+73 a_{1}+46 a_{2}+38 a_{3}+61 a_{4}+72 a_{5}+42 a_{6}+69 a_{7}+62 a_{8}+73 a_{9}+91 a_{10}+61 a_{11}+73 a_{12}+68 a_{13}=1037 \\
& 12 a_{0}+46 a_{1}+30 a_{2}+24 a_{3}+39 a_{4}+45 a_{5}+27 a_{6}+43 a_{7}+40 a_{8}+46 a_{9}+58 a_{10}+39 a_{11}+45 a_{12}+42 a_{13}=632 \\
& 10 a_{0}+38 a_{1}+24 a_{2}+20 a_{3}+32 a_{4}+38 a_{5}+22 a_{6}+38 a_{7}+32 a_{8}+38 a_{9}+53 a_{10}+32 a_{11}+38 a_{12}+36 a_{13}=538 \\
& 16 a_{0}+61 a_{1}+39 a_{2}+32 a_{3}+52 a_{4}+60 a_{5}+35 a_{6}+57 a_{7}+52 a_{8}+61 a_{9}+77 a_{10}+51 a_{11}+61 a_{12}+57 a_{13}=832 \\
& 19 a_{0}+72 a_{1}+45 a_{2}+38 a_{3}+60 a_{4}+73 a_{5}+42 a_{6}+69 a_{7}+60 a_{8}+72 a_{9}+91 a_{10}+61 a_{11}+72 a_{12}+69 a_{13}=10751 \\
& 11 a_{0}+42 a_{1}+27 a_{2}+22 a_{3}+35 a_{4}+42 a_{5}+25 a_{6}+40 a_{7}+36 a_{8}+42 a_{9}+53 a_{10}+36 a_{11}+41 a_{12}+39 a_{13}=607 \\
& 18 a_{0}+69 a_{1}+43 a_{2}+38 a_{3}+57 a_{4}+69 a_{5}+40 a_{6}+66 a_{7}+58 a_{8}+69 a_{9}+86 a_{10}+58 a_{11}+69 a_{12}+65 a_{13}=1012 \\
& 16 a_{0}+62 a_{1}+40 a_{2}+32 a_{3}+52 a_{4}+60 a_{5}+36 a_{6}+58 a_{7}+56 a_{8}+62 a_{9}+78 a_{10}+52 a_{11}+60 a_{12}+56 a_{13}=884 \\
& 19 a_{0}+73 a_{1}+46 a_{2}+38 a_{3}+61 a_{4}+72 a_{5}+42 a_{6}+69 a_{7}+62 a_{8}+73 a_{9}+91 a_{10}+61 a_{11}+73 a_{12}+68 a_{13}=1037 \\
& 24 a_{0}+91 a_{1}+58 a_{2}+53 a_{3}+77 a_{4}+91 a_{5}+53 a_{6}+86 a_{7}+78 a_{8}+91 a_{9}+116 a_{10}+77 a_{11}+90 a_{12}+86 a_{13}=1288 \\
& 16 a_{0}+61 a_{1}+39 a_{2}+32 a_{3}+51 a_{4}+61 a_{5}+36 a_{6}+58 a_{7}+52 a_{8}+61 a_{9}+77 a_{10}+52 a_{11}+60 a_{12}+57 a_{13}=876 \\
& 19 a_{0}+73 a_{1}+45 a_{2}+38 a_{3}+61 a_{4}+72 a_{5}+41 a_{6}+69 a_{7}+60 a_{8}+73 a_{9}+90 a_{10}+60 a_{11}+75 a_{12}+69 a_{13}=1025
\end{aligned}
$$




\subsection{Results and Discussion}

Solution of equations yielded the following results:

(1) $\mathrm{a}_{0}=223.099$ (2) $\mathrm{a}_{1}=-454.103$ (3) $\mathrm{a}_{2}=0.013$ (4) $\mathrm{a}_{3}=-8.2 \mathrm{E}-12$ (5) $\mathrm{a}_{4}=0.001$ (6) $\mathrm{a}_{5}=241.755$

(7) $\mathrm{a}_{6}=-3.8 \mathrm{E}-13$ (8) $\mathrm{a}_{7}=9.169$ (9) $\mathrm{a}_{8}=116.302$ (10) $\mathrm{a}_{9}=45.393$ (11) $\mathrm{a}_{10}=-3.668$ (12) $\mathrm{a}_{11}=0.013$

(13) $\mathrm{a}_{12}=206.936(14)-196.91$

The model obtained is given by Equation 28.

$\mathrm{Y}=223.099-454.103 \mathrm{X}_{1}+0.013 \mathrm{X}_{2}-8.2 \mathrm{E}-12 \mathrm{X}_{3}+0.001 \mathrm{X}_{4}+241.755 \mathrm{X}_{5}-3.8 \mathrm{E}-13 \mathrm{X}_{6}+9.169 \mathrm{X}_{7}+$ $116.302 X_{8}+45.393 X_{9}-3.668 X_{10}+0.013 X_{11}+206.936 X_{12}-196.910 X_{13}$

The standard error of estimate was computed using Equation 29 from parameters obtained from Table 7.

Table 7: Standard Error Estimation from Equation (28)

\begin{tabular}{ccccc}
\hline $\begin{array}{c}\text { Name of } \\
\text { Location }\end{array}$ & $\begin{array}{c}\text { Actual value of } \\
\text { Y from FRSC }\end{array}$ & $\begin{array}{c}\text { Value of Y from } \\
\text { Model Obtained }\end{array}$ & Error $(\mathbf{e})=\mathbf{Y}-\mathbf{Y}_{\mathbf{e}}$ & $\left(\mathbf{Y}-\mathbf{Y}_{\mathbf{e}}\right)^{\mathbf{2}}$ \\
\hline PZ & 79 & 78.995 & 0.005 & 0.000025 \\
RCC & 69 & 68.995 & 0.005 & 0.000025 \\
NNPC & 25 & 24.995 & 0.004 & 0.000025 \\
CJ & 39 & 38.996 & 0.004 & 0.000016 \\
BBP & 57 & 56.995 & 0.005 & 0.000025 \\
\hline \multicolumn{5}{r}{} \\
\end{tabular}

$$
\begin{aligned}
& \text { S.E }=\sqrt{\frac{\Sigma\left(Y-Y_{e}\right)^{2}}{N}} \\
& \text { S.E }=\sqrt{\frac{0.000116}{5}}=\sqrt{0.00000232} \\
& \text { S.E }=\mathbf{0 . 0 0 1 5 2}
\end{aligned}
$$

The standard error implies that $95 \%$ of the observation should fall within \pm 2 *standard error of the regression from the regression line which is also a quick approximation of a $95 \%$ prediction interval. From the analysis above, it shows that $95 \%$ of the observed values are at an average distance of $\mathbf{\pm 0 . 3 0 5 \%}$ from the fitted line.

\subsection{Model Validation}

The computation of the Coefficient of Determination is presented in Table 8 and 9.

Table 8: Total Sum of Error Estimation

\begin{tabular}{ccccc}
$\begin{array}{c}\text { Name of } \\
\text { Location }\end{array}$ & $\begin{array}{c}\text { Value of Y from } \\
\text { Model Obtained }\end{array}$ & $\begin{array}{c}\text { Mean of Actual } \\
\text { Value of } \mathbf{Y}\end{array}$ & $\mathbf{Y}-\overline{\mathbf{Y}}$ & $(\mathbf{Y}-\overline{\mathbf{Y}})^{\mathbf{2}}$ \\
\hline PZ & 79 & 53.8 & 25.2 & 635.04 \\
RCC & 69 & 53.8 & 15.2 & 231.04 \\
NNPC & 25 & 53.8 & -28.8 & 829.44 \\
CJ & 39 & 53.8 & -14.8 & 219.04 \\
BBP & 57 & 53.8 & 3.2 & 10.24 \\
\hline & & $\boldsymbol{\Sigma}(\mathbf{Y}-\overline{\mathbf{Y}})=\mathbf{0}$ & $\boldsymbol{\Sigma}(\mathbf{Y}-\overline{\mathbf{Y}})^{\mathbf{2}=\mathbf{1 9 2 4 . 8}}$ \\
\hline
\end{tabular}




$$
\overline{\mathrm{Y}}=\frac{\Sigma Y}{N}=\frac{79+69+25+39+57}{5}=\frac{269}{5}=53.8
$$

$\mathrm{S}_{\mathrm{YY}}=1924.8$

Table 9: Sum of Regression Error Estimation

\begin{tabular}{ccccc}
\hline $\begin{array}{c}\text { Name of } \\
\text { Location }\end{array}$ & $\begin{array}{c}\text { Actual value of } \\
\text { Y from FRSC }\end{array}$ & $\begin{array}{c}\text { Mean of Actual } \\
\text { Value of } \mathbf{Y}\end{array}$ & $\mathbf{Y}-\overline{\mathbf{Y}}$ & $(\mathbf{Y}-\overline{\mathbf{Y}})^{\mathbf{2}}$ \\
\hline PZ & 78.995 & 53.8 & 25.195 & 634.788 \\
RCC & 68.995 & 53.8 & 15.195 & 230.888 \\
NNPC & 24.995 & 53.8 & -28.805 & 829.728 \\
CJ & 38.996 & 53.8 & -14.804 & 219.158 \\
BBP & 56.995 & 53.8 & 3.195 & 10.208 \\
\hline \multicolumn{5}{r}{} \\
& & $\mathbf{\Sigma}(\mathbf{Y}-\overline{\mathbf{Y}})=\mathbf{- 0 . 0 2 9}$ & $\mathbf{\Sigma}(\mathbf{Y}-\overline{\mathbf{Y}})^{\mathbf{2}}=\mathbf{1 9 2 4 . 7 7}$ \\
\hline
\end{tabular}

$\overline{\mathbf{Y}}=\frac{\Sigma Y}{N}=\frac{79+69+25+39+57}{5}=\frac{269}{5}=53.8$

$\mathrm{SS}_{\mathrm{E}}=1924.77$

Residual Error $\left(\mathrm{SS}_{\mathrm{R}}\right)=1924.8-1924.77=0.03$

$$
\mathrm{R}^{2}=\frac{1924.77}{1924.8}=0.99998
$$

The coefficient of determination $\mathrm{R}^{2}$ which represents the percent of the data that is closest to the line of best fit, gives an indication from the analysis above, that $99.998 \%$ of the total variation in the observed value can be explained by the linear relationship between the factors influencing accident occurrence and the rate of accident per annual (as described by the regression equation). The other $0.00002 \%$ of the total variation in the rate of accident per annual remains unexplained.

The other form of validation was done by plotting a graph of the intersection location with the observed data and the estimated data as shown by the Figure 1 .

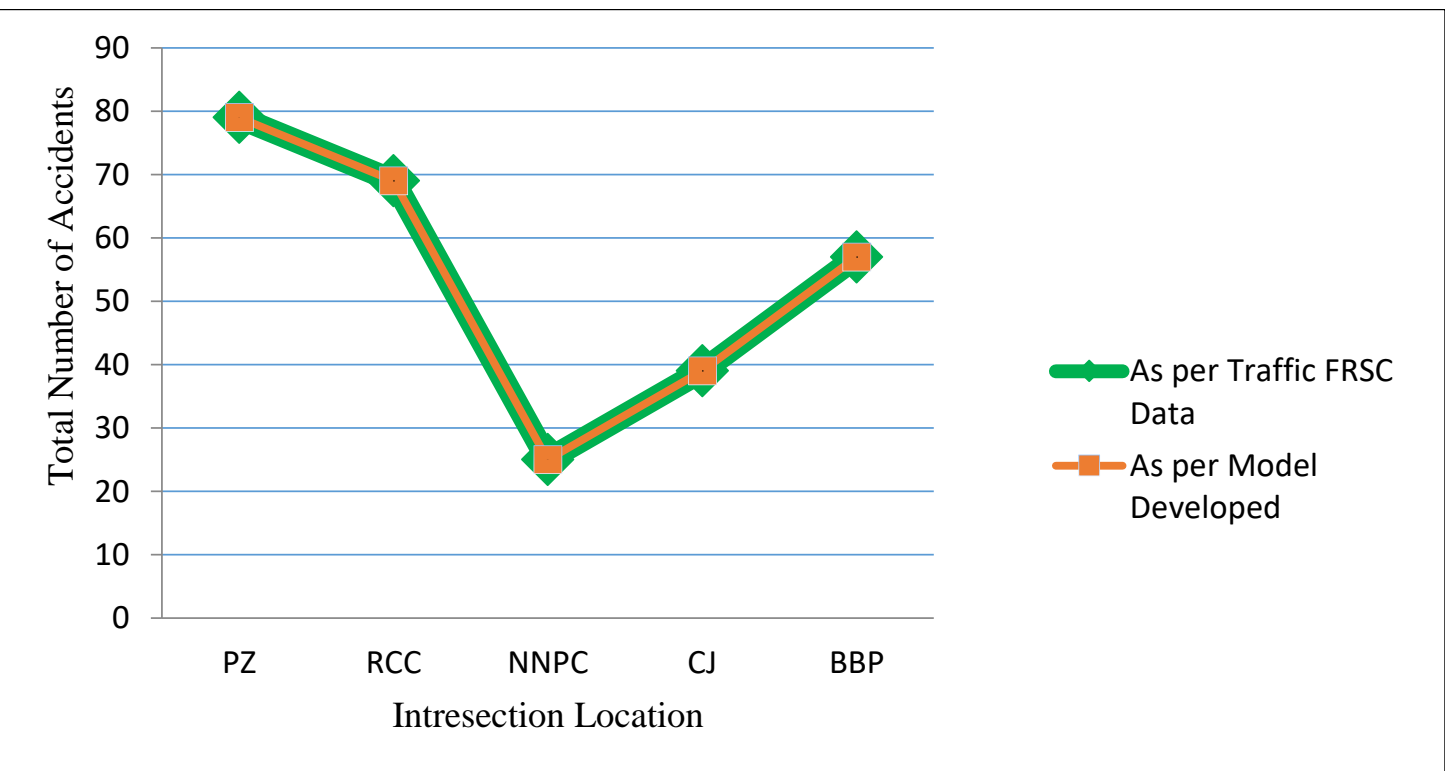

Figure 1: Comparison of total number of accidents found by model with the data obtained from the FRSC head office based on actual site conditions.

The graph above shows a very high approximate fitness of the observed and estimated data for a particular intersection. This close fitness between the observed and estimated values indicates that the predictive model holds a better predictability tendency. 


\subsection{Conclusion}

The proposed objective was to obtain a predictive model to establish a relationship between the factors influencing accident occurrence and number of accident and estimation of accident rate at some selected sites in Benin City. This project took into consideration total crash rate; a similar procedure which could be used for injurious crashes (minor or severity cases) or death case only. The predictive model developed using multiple regression method can be used for accident analysis on road network since most of the factors considered are similar.

However, the suitability of the model developed to the data can be measured using many coefficients but the coefficient of multiple determination and standard error of estimate was used in this project and as well the functional form of the model was designed to reproduce the data (observed). The accident predictive model presented here should be improved: more information will be needed and other variables should be analysed for this purpose while other variables will require further perfection.

The predictive model so obtained can contribute to planning phase preceding the designed intervention. This pertain to the programming of intersection operations (also laid out in regulations), which make it possible to target the spending of public funds by local of national administration or directing infrastructure, depending on the number of crashes predicted by the model. Especially as it concerns the evaluation and programming of road safety improvement operations which are to be adopted in the provincial road networks, concentrating on those areas of the infrastructural network that are deemed "critical" from a safety point of view is necessary.

\section{References}

Agbonkhese, O, Yisa, G.L, Agbonkhese, E.G, Akanbi, D.O, Aka, E.O, Mondigha, E.B (2013). RoadTraffic Accidents in Nigeria: Causes and Preventive Measures. Civil and Environmental Research, ISSN 2224-5790 (Paper) ISSN 2225-0514 (Online), Vol.3, No.13

Ali et al (2009). Sensitivity Analysis of Accident Prediction Model by Fractional Factorial Method. Accident Analysis \& Prevention, 39(1), pp.63-68.

Fajaruddin, M. (2008). Black Spot Study and Accident Prediction Model Using Multiplication Linear Regression" Advancing and Integrating Construction Education, Research and Practice, August 4-5, 2008.

Fajaruddin, M., Ismail, Y. (2008). Blackspot Study and Accident Prediction Model Using Multiple Linear Regression, Universiti Tun Hussein Onn Malaysia.

Kulmala, R., (1995). Safety at Rural Three and Four-arm Junctions - Development of Accident Prediction Models, Espoo 1995, Technical Research Centre of Finland, VTT 233.

Miranda-Moreno L.F., FU L., Saccomanno F.F., Labbe A. (1908). Alternative Risk Models for Ranking Locations for Safety Improvement, Transportation Research Record, pp.1-8.

Neumann and Glennon (1982). Theoretical Model That Relates Accident on Crest Curves to Available Sight Distance'

Nicholas J. Garber, Lester A. Hoel (2002). Traffic \& Engineering, Bill Stenquist, University of Virginia. Oladepo, O. Brieger, R.(2006). Road Traffic Accidents: Applying the Brake to a Killing Tree.

Stevens J., (1986). Applied multivariate statistics for the social sciences, Lawrence Erlbaum Associate, Inc., Publishers, Hillsdale, N.J.

Ukoji (2014). Trends and Patterns of Road Accident in Nigeria

Velmajasiniene et al (2011). Analysis of Accidents Prediction Feasibility on the Roads of Lithuania. 